\title{
CORRECTION
}

\section{Correction to: Once episiotomy, always episiotomy?}

\author{
Ayala Zilberman $^{1} \mathbb{D} \cdot$ Eyal Sheiner $^{2} \cdot$ Orit Barrett $^{3} \cdot$ Batel Hamou $^{2} \cdot$ Tali Silberstein $^{2}$
}

Published online: 6 May 2019

๑) Springer-Verlag GmbH Germany, part of Springer Nature 2019

\section{Correction to: \\ Archives of Gynecology and Obstetrics (2018) 298:121-124 \\ https://doi.org/10.1007/s00404-018-4783-8}

The article "Once episiotomy, always episiotomy?" written by Tali Silberstein, was originally published electronically on the publisher's internet portal (currently SpringerLink) on May 21, 2018 with open access.

With the author(s)' decision to step back from Open Choice, the copyright of the article changed to $($ S SpringerVerlag GmbH Germany, part of Springer Nature 2019 and the article is forthwith distributed under the terms of copyright.

The Original article has been corrected.
The original article can be found online at https://doi.org/10.1007/ s00404-018-4783-8.

\section{Tali Silberstein}

talisil@bgu.ac.il

1 Faculty of Health Sciences, Joyce \& Irving Goldman Medical School, Ben-Gurion University of the Negev, Beersheba, Israel

2 Department of Obstetrics and Gynecology, Soroka University Medical Center, Ben-Gurion University of the Negev, Beersheba, Israel

\footnotetext{
Department of Medicine and Clinical Research Center, Soroka University Medical Center, Ben-Gurion University of the Negev, Beersheba, Israel
}

Acknowledgment This study is part of the requirements for MD from Joyce \& Irving Goldman Medical School, Faculty of Health Sciences Ben-Gurion University of the Negev.

Publisher's Note Springer Nature remains neutral with regard to jurisdictional claims in published maps and institutional affiliations. 